\title{
Facile grafting of bioactive cellulose derivatives onto PVC surfaces
}

\author{
Sandra Bigot ${ }^{\mathrm{a}}$, Guy Louarn ${ }^{\mathrm{b}}$, Nasreddine Kébir ${ }^{\mathrm{a}, *}$, Fabrice Burel ${ }^{\mathrm{a}}$ \\ a Normandie Université, INSA de Rouen, CNRS UMR 6270 FR 3038, 685 avenue de l'université BP08, 76801 Saint-Etienne du Rouvray, cedex, France \\ b Institut des Matériaux Jean Rouxel (IMN), UMR 6502, CNRS-Université de Nantes, 2 rue de la Houssinière, BP 32229, 44322 Nantes, France
}

Bioactive methyl cellulose and hydroxyethyl cellulose were successfully grafted onto PVC films using a two-step pathway. PVC surface was first modified with isothiocyanate in DMSO/water medium. Then, unmodified polysaccharides were directly grafted onto the thiocyanated surface in acetonitrile/DMSO mixture, in presence of DBTL as catalyst. The polysaccharide grafting onto the PVC surface was evidenced by contact angle measurements, AFM and XPS.

\section{Introduction}

Biofilm formation and infection is a problem of major concern covering several applications fields, especially the Biomaterials one. In order to prevent this phenomenon, several strategies were developed in the past such as: antibiotic impregnation, surface coating by some metals like copper and silver or by some specific polymers like hydrogels. However, these techniques exhibited some disadvantages such as antibiotic exhaustion, appearance of bacteria resistance phenomena, physical instability and lost of the biological activity in the long term.

During the last decades, a promising strategy consisting in surface modification was developed. This strategy employed either physical treatment such as plasma, or direct chemical treatment such as grafting of specific species and functionalities. In this context, the wet-chemical process has been found to be the best pathway to control the surface chemical and physical properties, in particular when active polymers are grafted onto the surface. Indeed, comparing to small molecules, polymer grafting offers numerous advantages such as surface stability and longevity, high surface coating and high bioactivity.

Polyvinyl chloride (PVC) is one of the most important polymers thanks to its versatile physico-chemical and biological properties. PVC is employed in various applications such as construction, packaging and medical devices. Many medical articles are based on PVC such as: blood bags, indwelling catheters, urinary catheters etc.

\footnotetext{
* Corresponding author. Tel.: +33 0232956576; fax: +33 0232956644 E-mail address: nasreddine.kebir@insa-rouen.fr (N. Kébir).
}

Polysaccharides represent a major natural, renewable and available resource in the polymer field. Their applications vary from textile [1,2] to medical systems [3-15]. They are non-toxic, biocompatible, often biodegradable and water soluble. Such properties make them suitable for many uses in the biomedical field, health care, or drug delivery systems [3]. As example, heparin and chitosan, are used to improve biocompatibility and/or to prevent attachment of bacteria, blood platelets or proteins onto biomaterial surfaces [4-15]. Recently, cellulose derivatives, especially methyl celluloses, have been described as potent bacteria repellents when they are grafted onto a silicone surface [12].

Nevertheless, in the literature only few examples describe the grafting of polysaccharides onto PVC surfaces. Mao et al. [13] grafted $O$-butyrylchitosan (OBCS) onto PVC surface in order to improve blood compatibility. OBCS was first bound to 4azidobenzoic acid, coated on the PVC film surface and then, it was covalently immobilized by ultraviolet irradiations. In order to prevent bacteria attachment, Asadinezhad et al. [14] functionalized PVC surface by a multistep procedure. In a first step, the surface was activated by discharge plasma in air. Then, acrylic acid was polymerized from the surface via a radical graft copolymerization and in a final step chitosan layers were grafted onto the surface by amidification. With the aim of mimicking the nonthrombogenic properties of the endothelial cell, Zhou et al. [15] reported the development of a new generation of NO release polymeric coatings that employ NO release chemistry in combination with surface immobilized active heparin. Heparin was grafted onto aminated PVC after modification of the polysaccharide chains with $N$-hydroxysuccinimide, using 1 ethyl-3-(3-dimethylaminopropyl)carbodiimide as coupling agent. All these examples support the need of alternative procedures to graft polysaccharides onto PVC. 
Herein, we describe a simple and an alternative procedure for the grafting of polysaccharides onto PVC surfaces. First, isothiocyanate groups (NCS) were introduced onto PVC surfaces using potassium thiocyanate in a water/DMSO mixture. These groups are analogue to isocyanate (NCO) groups, and are commonly present in fluorescent probes for protein labelling. Then, cellulose derivatives exhibiting bacteria repellent properties [12] were directly grafted onto PVC-NCS surfaces in presence of a catalyst. The grafting efficiency was assessed by mean of contact angle measurements, XPS and AFM analysis.

\section{Experimental}

\subsection{Materials}

Commercial bulk polymerized PVC was obtained from Sigma-Aldrich, Lyon, France. The average molecular weights determined by SEC were $\bar{M}_{n}=47000 \mathrm{~g} / \mathrm{mol}$ and $\bar{M}_{w}=80000 \mathrm{~g} / \mathrm{mol}$. Methyl cellulose (DS=1.5-1.9), hydroxyethyl cellulose (DS=1.6) and tetrabutylammonium hydroxide (TBAH, $40 \mathrm{wt} \%$ in water) were purchased from Sigma-Aldrich. Potassium thiocyanate was purchased from Merck.

\subsection{Characterizations}

NMR spectra were recorded on a Bruker Avance (300 MHz)Spectrometer.

IR spectra were recorded on a FTIR (Perkin-Elmer) equipped with a diamond ATR device (attenuated total reflection).

XPS measurements were carried out at room temperature. An Axis Nova instrument from Kratos Analytical spectrometer with Al $\mathrm{K} \alpha$ line $(1486.6 \mathrm{eV})$ as excitation source has been used. The core level spectra were acquired with an energy step of $0.1 \mathrm{eV}$ and using a constant pass energy mode of $20 \mathrm{eV}$, to obtain data in a reasonable experimental time (energy resolution of $0.4 \mathrm{eV}$ ). The pressure in the analysis chamber was maintained lower than $10^{-7} \mathrm{~Pa}$. The background spectra were considered as Shirley type and curve fitting was achieved with a mixture of Gaussian-Lorentzian functions [16]. The error in defining the position of peaks was estimated at about $0.1 \mathrm{eV}$. No surface cleaning, using Ar sputtering for example was made. We know from experience that carbonaceous atmospheric contamination on material usually occurs, but in our case, ion sputtering can be suspected of changing chemical composition and inducing structural damage.

Surface energy of the materials were evaluated using Digidrop Goniometer (GBX, France), by static contact angle $\left(\theta_{i}\right)$ measurements on the sample surfaces with 3 liquids: water, diiodomethane and glycerol. The static contact angles were measured at the equilibrium time. At least, five measurements on different surfaces were performed to calculate the mean contact angle and its standard deviation. According to the Owens-Wendt relationship (1) the dispersive $\gamma_{s}^{d}$ and polar $\gamma_{s}^{p}$ components of the surface energies $\left(\gamma_{s}=\gamma_{s}^{d}+\gamma_{s}^{p}\right)$ of the samples were determined.

$\frac{\left(1+\cos \theta_{i}\right) \gamma_{i}}{2 \sqrt{\gamma_{i}^{d}}}=\sqrt{\gamma_{s}^{p}} \times \sqrt{\frac{\gamma_{i}^{p}}{\gamma_{i}^{d}}}+\sqrt{\gamma_{s}^{d}}$

where $\gamma_{i}, \gamma_{i}^{d}, \gamma_{i}^{p}$ are the solvent superficial tension parameters.

Surface polarities $(P)$ of the materials are calculated using Eq. (2):

$P=\frac{\gamma_{s}^{p}}{\gamma_{s}} \times 100$

An AFM microscope (JPK instruments, NanoWizard, Berlin, Germany) was used for imaging and roughness measurements.
AFM images were obtained by using the intermittent contact mode AFM in air. Classical silicon cantilevers were used (NanoWorld Pointprobe ${ }^{\circledR}$ NCHR). The average force constant and resonance were approximately $42 \mathrm{~N} / \mathrm{m}$ and $320 \mathrm{kHz}$, respectively. Topographic images were taken at different locations on the surface, in order to account for any heterogeneity in the coverage of the polysaccharides. AFM data were analyzed by the software SPM Image Processing v.3 from JPK Instruments, to extract the surface roughness (calculated on a $10 \mu \mathrm{m}^{2}$ area).

\subsection{Preparation of PVC films}

About $1 \mathrm{~g}$ of PVC powder was dissolved in $40 \mathrm{~mL}$ of dichloromethane and poured into a Teflon mould. PVC films were then obtained by slow solvent evaporation under nitrogen atmosphere.

\subsection{Preparation of PVC-isothiocyanate surfaces (PVC-NCS)}

In a round bottom flask, $\mathrm{KSCN}\left(9.0 \times 10^{-2} \mathrm{~mol}\right)$ and TBAH $\left(4.5 \times 10^{-2} \mathrm{~mol}\right)$ were dissolved in a $60 \mathrm{~mL}$ of DMSO/water $(4 / 1)$ mixture. PVC sheets $(1 \mathrm{~cm} \times 1 \mathrm{~cm})$ were immersed and the medium was heated at $60^{\circ} \mathrm{C}$ for $17 \mathrm{~h}$ under slow-stirring. Then, the PVC sheets were thoroughly washed with water, rinsed with diethyl ether and dried at $60^{\circ} \mathrm{C}$. The same reaction mixture could be recycled 4-5 times.

FTIR: $v_{\max } / \mathrm{cm}^{-1} \ldots 2150(\mathrm{~S}-\mathrm{CN}), 2051(\mathrm{~N}=\mathrm{C}=\mathrm{S}), 1600(\mathrm{C}=\mathrm{C})$.

\subsection{Grafting of polysaccharides onto PVC-NCS surfaces}

In a round bottom flask equipped with a magnetic stirrer, $12 \mathrm{mg}$ of polysaccharide were dissolved in $2 \mathrm{~mL}$ of DMSO at room temperature. Then, $4-12 \mathrm{~mL}$ (Table 1 ) of acetonitrile were added and the mixture was heated to $60^{\circ} \mathrm{C}$. Then, 0.05 equivalent of DBTL with regards to the polysaccharide hydroxyl groups were added. After, PVC sheets were immersed in this solution under gentile stirring for $24 \mathrm{~h}$. The treated PVC films were washed several times with water and then put in water bath under ultra sound $(30 \mathrm{~min})$, rinsed with diethyl ether and dried at $60^{\circ} \mathrm{C}$.

\section{Results and discussion}

\subsection{Preparation of grafted and ungrafted PVC-NCS surfaces}

The common strategy to directly graft a polysaccharide onto polymer surfaces consists in esterification reaction between the polysaccharide hydroxyl groups and surface carboxyl groups, in presence of coupling agents such as $\mathrm{N}, \mathrm{N}$-dicyclohexylcarbodiimide (DCC) or $N, N^{\prime}$-carboimidazole (CDI). In this study, an original procedure involving isothiocyanate groups was developed since these groups are easier to introduce onto the PVC chains compared to carboxyl groups. The chemical grafting of polysaccharides onto PVC surfaces was achieved in two steps (Scheme 1).

In a first step, isothiocyanate groups were introduced onto PVC surfaces. Actually, the reaction of thiocyanates with an alkyl halide is a nucleophilic substitution (SN2) that results in the formation of the corresponding alkyl isothiocyanate. The reaction proceeds in homogenous or heterogeneous conditions and may be applied to polymers as well. Thus, it has be shown [17] that thiocyanation of PVC surfaces can be achieved in a solid/liquid two phase system in the presence of a phase transfer catalyst in aqueous media. A similar heterogeneous procedure was used herein to apply the reaction to the PVC surface. Chloride groups were substituted by isothiocyanate groups (-NCS) using $\mathrm{KSCN}$, in the presence of TBAH as phase transfer catalyst in a DMSO/water (4/1) mixture. 
Table 1

Experimental conditions and static contact angle data relative to PVC surfaces.

\begin{tabular}{|c|c|c|c|c|c|c|c|c|}
\hline Entry & Surface & $M_{\mathrm{w}}(\mathrm{g} / \mathrm{mol})$ & DBTL (equiv./OH) & $\mathrm{CH}_{3} \mathrm{CN} / \mathrm{DMSO}(\mathrm{v} / \mathrm{v})$ & Static $\theta_{\text {water }}\left({ }^{\circ}\right)^{\mathrm{a}}$ & $\gamma^{d}(\mathrm{mN} / \mathrm{m})^{\mathrm{a}}$ & $\gamma^{p}(\mathrm{mN} / \mathrm{m})^{\mathrm{a}}$ & Polarity (\%) \\
\hline 1 & PVC & 1 & I & 1 & $89 \pm 5$ & $42.2 \pm 0.2$ & $1.0 \pm 0.8$ & $2.3 \pm 1.8$ \\
\hline 2 & PVC-NCS & i & I & $0 / 0 ; 2 / 1 ; 4 / 1 ; 6 / 1$ & $44 \pm 2$ & $38.9 \pm 1.3$ & $18.9 \pm 0.1$ & $32.7 \pm 0.7$ \\
\hline 3 & PVC-MeC 1 & 41,000 & 0.00 & $6 / 1$ & $47 \pm 2$ & $36.9 \pm 0.7$ & $18.1 \pm 0.1$ & $32.9 \pm 0.3$ \\
\hline 4 & PVC-MeC 1 & 41,000 & 0.02 & $6 / 1$ & $45 \pm 1$ & $38.6 \pm 3.2$ & $19.9 \pm 0.3$ & $34.0 \pm 2.1$ \\
\hline 5 & PVC-MeC 1 & 41,000 & 0.05 & $6 / 1$ & $59 \pm 2$ & $39.0 \pm 1.6$ & $11.9 \pm 0.2$ & $23.4 \pm 0.9$ \\
\hline 6 & PVC-MeC 2 & 88,000 & 0.00 & $2 / 1$ & $48 \pm 2$ & $38.7 \pm 0.4$ & $17.6 \pm 0.6$ & $31.3 \pm 0.6$ \\
\hline 7 & PVC-MeC 2 & 88,000 & 0.05 & $2 / 1$ & $60 \pm 4$ & $37.4 \pm 0.5$ & $11.0 \pm 1.4$ & $22.7 \pm 2.4$ \\
\hline 8 & PVC-HEC 1 & 720,000 & 0.00 & $2 / 1$ & $43 \pm 2$ & $38.3 \pm 0.4$ & $19.4 \pm 0.3$ & $33.6 \pm 0.2$ \\
\hline 9 & PVC-HEC 1 & 720,000 & 0.02 & $2 / 1$ & $45 \pm 1$ & $37.4 \pm 0.3$ & $19.2 \pm 0.2$ & $33.9 \pm 0.1$ \\
\hline 10 & PVC-HEC 1 & 720,000 & 0.05 & $2 / 1$ & $65 \pm 2$ & $41.4 \pm 0.4$ & $7.1 \pm 0.9$ & $14.6 \pm 0.9$ \\
\hline 11 & PVC-HEC 2 & 250,000 & 0.00 & $4 / 1$ & $41 \pm 3$ & $40.2 \pm 0.8$ & $18.7 \pm 0.5$ & $31.7 \pm 0.7$ \\
\hline 12 & PVC-HEC 2 & 250,000 & 0.05 & $4 / 1$ & $55 \pm 1$ & $37.8 \pm 0.8$ & $13.6 \pm 0.4$ & $26.5 \pm 1.4$ \\
\hline
\end{tabular}

a $\theta_{\text {water }}$ : contact angle with water; $\gamma^{d}$ : dispersive component of the surface energy; $\gamma^{p}$ : polar component of the surface energy.
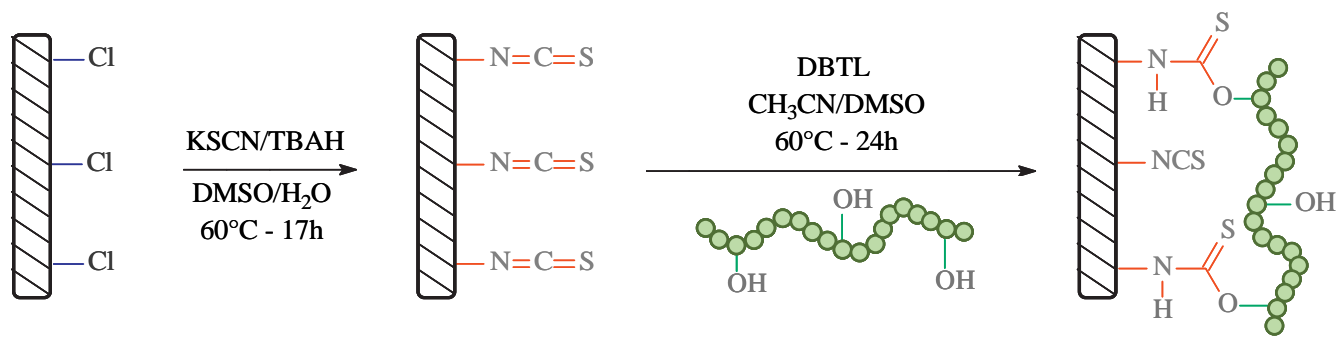

Scheme 1. The chemical pathway used to graft polysaccharides onto PVC surface.

In a second step, methylcellulose and hydroxyethylcellulose with different molecular weights were dissolved at a concentration of $1 \mathrm{mg} / \mathrm{mL}$ in appropriate acetonitrile/DMSO mixtures in which the PVC films was not dissolved or damaged (Table 1). Then, an optimal amount of a catalyst, i.e., dibutyltin dilaurate (DBTL), was added (Table 1). After, the PVC-NCS samples were immersed in the polysaccharide solution during $24 \mathrm{~h}$ at $60^{\circ} \mathrm{C}$, to allow the chemical grafting. The obtained PVC grafted polysaccharide surfaces were thoroughly cleaned before characterizations.

\subsection{Surface characterisations}

\subsubsection{Contact angle measurements}

The contact angle measurement was a quick, simple and efficient method to control the chemical grafting of polysaccharides onto the PVC-NCS surface and to optimize the experimental conditions.

Static contact angles with water as well as surface energies and polarities of the modified and unmodified PVC surfaces are reported in Table 1.

Comparing to PVC surface, the PVC-NCS surface showed a significant decrease of the static contact angle with water, i.e., from $89^{\circ}$ to $44^{\circ}$, indicating that thiocyanation increased considerably the hydrophilicity of the PVC surface. In addition, the polar component of the surface energy increased from 1 to $19 \mathrm{mN} / \mathrm{m}$ and the surface polarity increased from $2.3 \%$ to $32.7 \%$ (Table 1, entries 1 and 2 ).

Static contact angles with water of PVC-NCS surfaces that were in contact with polysaccharides were dependent on the amount of DBTL with regards to polysaccharide hydroxyl groups. For 0 and 0.02 equiv. of DBTL/OH (Table 1 , entries 3, 4, 6, 8, 9 and 11), one can observe that the contact angle as well as surface energy and polarity were very close to those of the PVC-NCS surface (Table 1, entry 2), which suggest that chemical grafting did not happen in these conditions. For 0.05 equiv. of DBTL/OH (Table 1 , entries 5, 7 , 10 and 12), the surface properties changed significantly, suggesting that the chemical grafting of polysaccharide onto the PVC-NCS surfaces were successful. Actually, the two methylcellulose surfaces exhibited similar properties, i.e., contact angles with water around $60^{\circ}$ and polarities around 23\%. However, hydroxyethyl cellulose surfaces were different; the PVC-HEC1 surface exhibited higher contact angle $\left(65^{\circ}\right.$ against $\left.55^{\circ}\right)$ and lower polarity (14.6\% against 26.5\%) comparing to PVC-HEC 2. Overall, the grafted surfaces were less -but still- hydrophilic and less polar than the ungrafted PVCNCS surface. These grafted surfaces were then characterized by FTIR, XPS and AFM.

Dynamic contact angle with water was also performed to assess the surface wettability (Table 2). The AA is characteristic of the wettability of the low-energy or hydrophobic part of the surface whereas the RA is more characteristic of the high-energy or hydrophilic part.

Native PVC surface exhibited AA around $90^{\circ}$ and RA around $43^{\circ}$. After thiocyanation, the AA and RA decreased dramatically and the balance between the two parts was also reduced as suggested by the decrease of hysteresis value from $48^{\circ}$ to $33^{\circ}$ (Table 2, entries 1 and 2).

PVC-NCS surfaces grafted with polysaccharides exhibited AA very close to static angle, whereas RA was in the range of $15-20^{\circ}$ (Table 2, entries 3-6). Thus, hysteresis values ranged from $35^{\circ}$ to $47^{\circ}$ and were consequently higher than the PVC-NCS hysteresis $\left(33^{\circ}\right)$. This behaviour is likely to be associated with the hydrophobic backbone of the polymer chains that increase the

Table 2

Dynamic contact angle data relative to PVC-NCS surfaces grafted with polysaccharide in presence of 0.05 equiv. of DBTL.

\begin{tabular}{lllll}
\hline \multirow{2}{*}{ Entry } & Surface & \multicolumn{2}{l}{ Dynamic $\theta_{\text {water }}\left(^{\circ}\right)$} \\
\cline { 3 - 4 } & & AA & RA & Hyst \\
\hline 1 & PVC (control 1) & $90 \pm 3$ & $43 \pm 5$ & $48 \pm 2$ \\
2 & PVC-NCS (control 2) & $46 \pm 2$ & $13 \pm 2$ & $33 \pm 3$ \\
3 & PVC-MeC 1 & $60 \pm 1$ & $15 \pm 1$ & $44 \pm 1$ \\
4 & PVC-MeC 2 & $60 \pm 1$ & $16 \pm 1$ & $45 \pm 1$ \\
5 & PVC-HEC 1 & $66 \pm 1$ & $19 \pm 1$ & $46 \pm 1$ \\
6 & PVC-HEC 2 & $53 \pm 1$ & $20 \pm 1$ & $33 \pm 2$ \\
\hline
\end{tabular}

AA: advancing angle; RA: receding angle; Hyst: hysteresis. 
Table 3

XPS data of the prepared surfaces: elemental analysis; peak assignment and contribution.

\begin{tabular}{|c|c|c|c|c|c|c|c|}
\hline Chemical state & Binding energy $(\mathrm{eV})$ & PVC & PVC-NCS & PVC-MeCell 1 & PVC-MeCell 2 & PVC-HEC 1 & PVC-HEC 2 \\
\hline$\% \mathrm{C}$ & - & 66.6 & 81.7 & 66.7 & 67.3 & 70.9 & 63.8 \\
\hline$\underline{\mathrm{C}}-(\mathrm{C}, \mathrm{H}), \underline{\mathrm{C}}=\underline{\mathrm{C}}$ & $284-285$ & 52.9 & 64.5 & 61.9 & 65.6 & 59.2 & 68.4 \\
\hline$\overline{\mathrm{C}}-\mathrm{S}, \underline{\mathrm{C}}-\overline{\mathrm{O}}, \underline{\mathrm{C}}-\mathrm{N}, \underline{\mathrm{C}}-\mathrm{Cl}, \mathrm{C}-\mathrm{C}-\mathrm{C}$ ring & 286.4 & 47.1 & 17.2 & 25.5 & 23.0 & 26.8 & 21.1 \\
\hline$\overline{\mathrm{O}}-\mathrm{C}-\mathrm{O}$ & 287.7 & 1 & 1 & 6.0 & 5.4 & 6.3 & 5.0 \\
\hline$(\underline{\mathrm{C}}=\overline{\mathrm{O}})-\mathrm{O}-(\underline{\mathrm{C}}=\mathrm{O})-\mathrm{NH}, \mathrm{NH}-(\underline{\mathrm{C}}=\mathrm{S})-\mathrm{O}$ & 288.9 & i & i & 6.6 & 5.9 & 6.9 & 5.5 \\
\hline$\% 0$ & - & 0 & $<1^{*}$ & 16.3 & 16.4 & 13.9 & 15.8 \\
\hline$-(\mathrm{C}=\underline{\mathrm{O}})-\mathrm{NH},(\mathrm{C}=\underline{\mathrm{O}})-\mathrm{O}-$ & 531.6 & 1 & 1 & 32.3 & 27.5 & 28.2 & 32.8 \\
\hline $\mathrm{C}-\mathrm{O}-\mathrm{C}, \mathrm{C}-\mathrm{O}-\mathrm{H}$ & 532.2 & i & 100 & 35.3 & 45.0 & 46.4 & 34.5 \\
\hline$-(\overline{\mathrm{C}}=0)-\underline{\mathrm{O}}$ & 533.4 & l & 1 & 32.3 & 27.5 & 28.2 & 32.8 \\
\hline$\% \mathrm{~N}$ & - & 0 & 1.5 & 1.7 & 1.5 & 1.5 & 1.6 \\
\hline $\mathrm{SCN}^{-}$ & 394.8 & 1 & 5.6 & 6.3 & 5.3 & 0.0 & 0.0 \\
\hline$-\overline{\mathrm{N}}=\mathrm{C}=\mathrm{S},(\mathrm{C}=\mathrm{O}) \underline{\mathrm{NH}}-\mathrm{S}-\mathrm{C} \equiv \mathrm{N},(\mathrm{C}=\mathrm{S}) \underline{\mathrm{NH}}$ & 399.9 & i & 74.2 & 69.6 & 63.0 & 61.5 & 74.5 \\
\hline $\mathrm{C}-\mathrm{N}^{+}$ & 401.5 & i & 20.2 & 24.6 & 31.7 & 38.5 & 25.5 \\
\hline$\% \mathrm{~S}^{-}$ & - & 0 & 1.3 & 1.4 & 1.6 & 1.2 & 1.6 \\
\hline $\mathrm{C}-\underline{\mathrm{S}}-\mathrm{CN}, \underline{\mathrm{S}} \mathrm{CN}^{-}$ & 136.8 & 1 & 52.7 & 40.9 & 48.7 & 45.1 & 31.5 \\
\hline$>C=\underline{S}$ & 168.1 & i & 47.3 & 59.1 & 51.3 & 54.9 & 68.5 \\
\hline$\% \mathrm{Cl}^{-}$ & & 33.4 & 15.5 & 12.0 & 10.4 & 10.3 & 15.9 \\
\hline
\end{tabular}

hydrophilic-hydrophobic balance of the surface. Besides, hysteresis can also be explained by surface heterogeneity, texture and roughness.

\subsubsection{Spectroscopic analysis}

The thiocyanation of PVC surface was followed by ATR-FTIR. The appearance of a new band at $\sim 2050 \mathrm{~cm}^{-1}$ attributed to isothiocyanate groups, according to literature [18], indicated once again that the reaction was successful. The detection of this band by this technique showed that the NCS groups were grafted on a PVC surface zone of $3 \mu \mathrm{m}$ of depth at least. This probably resulted from surface swelling in the DMSO/acetonitrile medium, which allowed the penetration of the thiocyanate ions. However, because of their big hydrodynamic volume, polysaccharides were only grafted on the extreme surface and were therefore not detected by this technique.

The elemental compositions of the grafted surfaces and their controls (PVC and PVC-NCS), were determined by XPS analysis. Results are shown in Table 3.

As expected, XPS survey scans obtained from the PVC surface gave two signals corresponding to $\mathrm{C}$ and $\mathrm{Cl}$ with contributions of $66.6 \%$ and $33.4 \%$, respectively. The elemental analysis of the PVCNCS surface confirmed the presence of $\mathrm{N}(1.5 \%)$ and S (1.3\%) coming from the isothiocyanate groups. However, the percentage of $\mathrm{Cl}$ decreased (15.5\%) suggesting an elimination of $\mathrm{HCl}$ (PVC dechlorination), which was not observed by FTIR. Kameda et al. [18] also observed this side reaction and have shown that the presence of phase transfer agents, such as TBAH, largely favoured the substitution reaction over the elimination one. The elemental analysis of the grafted surfaces showed the presence of $\mathrm{O}$ with abundance around 15\%, suggesting the presence of polysaccharides.

The XPS survey scans for the main components were analyzed to assign the peaks $\mathrm{C}_{1 \mathrm{~s}}, \mathrm{~N}_{1 \mathrm{~s}}$ and $\mathrm{S}_{2 \mathrm{p}}$ to chemical functions (Table 3 ). Typical examples of $C_{1 s}$ high resolution XPS spectra are presented in Fig. 1.

For PVC-NCS surface, the $C_{1 s}$ peak was decomposed into four peaks. The peaks ranging from 284 to $285 \mathrm{eV}$ are ascribed to $\mathrm{C}$ of saturated and unsaturated hydrocarbon chains. The peak at $286.4 \mathrm{eV}$ is attributed to $\mathrm{C}$ making single bonds with $\mathrm{N}, \mathrm{S}$ or $\mathrm{Cl}$. The contribution of this peak is weak (15.5\%) confirming the elimination of $\mathrm{Cl}$ during chemical treatment. The high resolution XPS spectra of the $\mathrm{N}_{1 \mathrm{~s}}$ region revealed three peaks. The peak at $394.8 \mathrm{eV}$ is owing to residual thiocyante ions adsorbed onto the surface. The peak at $399.9 \mathrm{eV}$ is ascribed to grafted isothiocyanate groups. The peak at 401.5 is due to ammonium groups of residual TBAH, which exhibited also a very weak signal at $532.2 \mathrm{eV}$, undetectable in the survey spectra $(<1 \%)$. The high resolution XPS spectra of the $S_{2 p}$ region revealed two peaks; each peak corresponds to two spin-orbit transitions. The main spin-orbit transition 3/2 was used for quantification. The peak at $163.8 \mathrm{eV}$ is ascribed to the $S$ in thiocyante groups and residual thiocyante ions. The peak at $168.1 \mathrm{eV}$ is ascribed to the $\mathrm{S}$ in isothiocyante groups.

The PVC-NCS surfaces grafted with polysaccharides exhibited a $\mathrm{C}_{1 \mathrm{~s}}$ peak at $286.4 \mathrm{eV}$ with increased intensity because of the supplemental contribution of carbons of $\mathrm{C}-\mathrm{O}$ and $\mathrm{C}-\mathrm{C}-\mathrm{C}$ bonds from polysaccharides rings. This peak contribution varied from $21 \%$ to
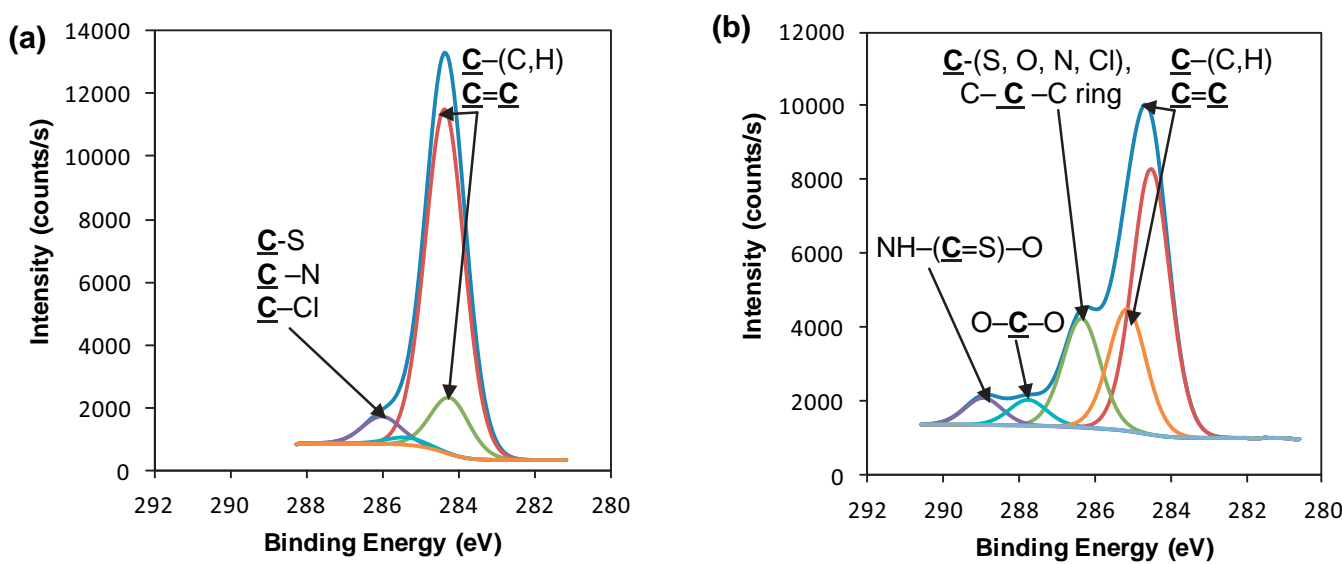

Fig. 1. XPS high resolution spectra of the $C_{1 \text { s }}$ region: (a) PVC-NCS and (b) PVC-MeC 2. 

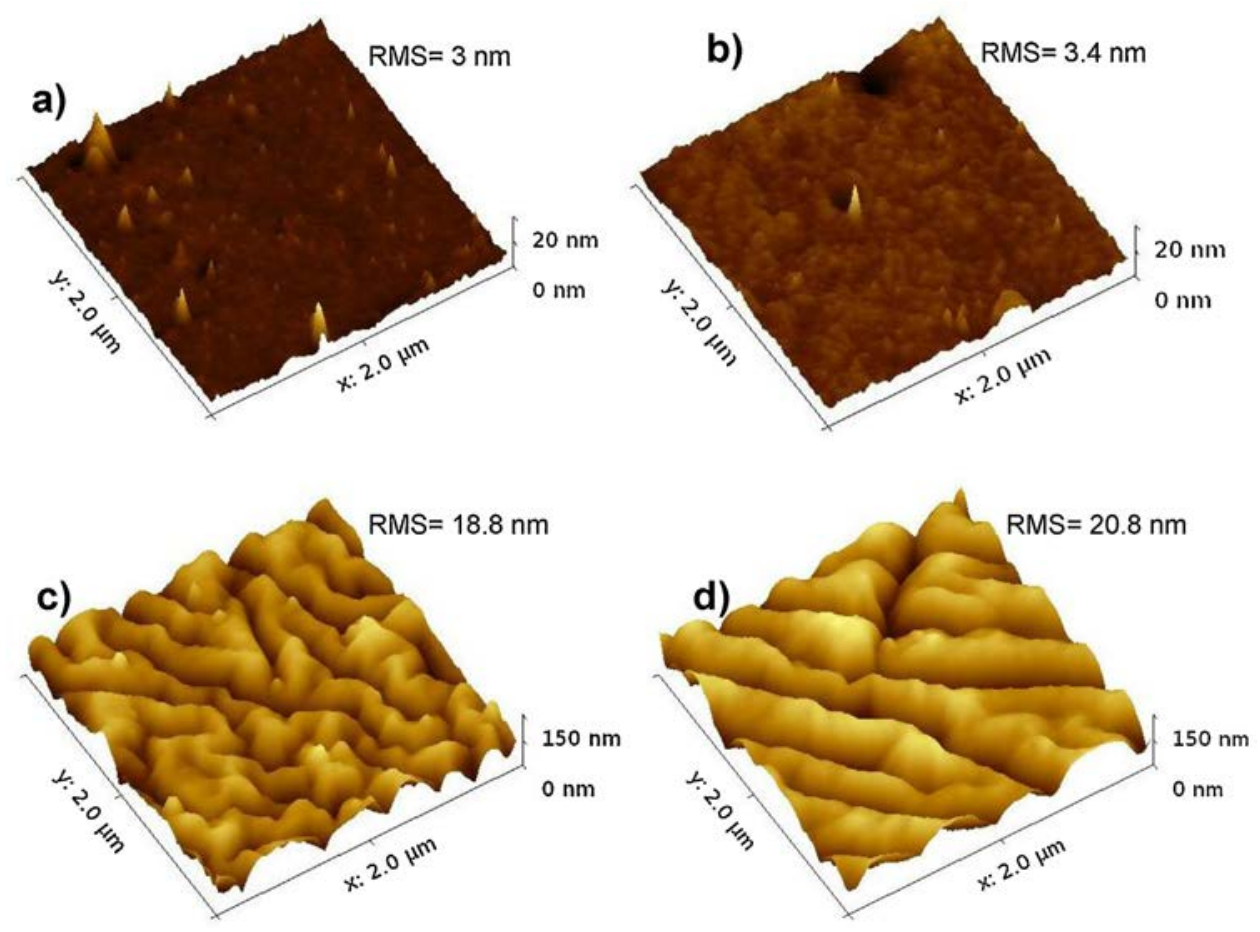

Fig. 2. IC-AFM height images $(10 \mu \mathrm{m} \times 10 \mu \mathrm{m})$ of (a) PVC, (b) PVC-NCS and (c) PVC-HEC 1 , (d) PVC-MeC 1.

$27 \%$ where about $17 \%$ was due to the surface control (PVC-NCS). In addition, two supplemental peaks were observed in the $C_{1 s}$ region, the peak at $287.7 \mathrm{eV}$ was ascribed to $\mathrm{C}$ in acetal or hemiacetal functions in polysaccharides. The peak at $288.9 \mathrm{eV}$ was attributed to $\mathrm{C}$ in the thiocarbamate links $(\mathrm{NH}-(\mathrm{C}=\mathrm{S})-\mathrm{O})$. The XPS high resolution spectra of the $\mathrm{N}_{1 \mathrm{~s}}$ and $\mathrm{S}_{2 \mathrm{p}}$ regions were similar to those of the PVC-NCS surface but with variable peak contributions.

\subsubsection{AFM analysis}

AFM images of PVC and PVC-NCS surfaces as well as typical examples of grafted surfaces are shown in Fig. 2.

One can observe that the surface treatment with NCS led to changes in surface morphology without significant variation in the surface roughness, which was around $3 \mathrm{~nm}$.

In contrast, polysaccharide grafting onto the PVC-NCS surface changed dramatically the surface topography, and the surface roughness increased to around $20 \mathrm{~nm}$.

Furthermore, according to the literature [19,20], the surface being homogeneous and roughness values being lower than $100-500 \mathrm{~nm}$, the hysteresis measured by dynamic contact angle with water would be exclusively due to the hydrophilic-hydrophobic balance.

\section{Conclusions}

In this work we have grafted bioactive cellulose derivatives onto PVC surfaces using a straightforward pathway. First, PVCNCS surfaces were prepared by a heterogeneous thiocyanation of the PVC surface in a DMSO/water mixture. Then, the selected polysaccharides were directly grafted onto the PVC-NCS surfaces in a DMSO/actonitrile media, in presence of DBTL as catalyst. The impact of DBTL amount on polysaccharide grafting onto the surface was monitored by contact angle measurements. 0.05 equiv. of DBTL by polysaccharide hydroxyl group seemed to be an optimal ration. In these conditions, the grafting reaction was effective and the resulted surfaces exhibited modulated properties comparing to the ungrafted surfaces.

\section{Acknowledgements}

This work was a part of the project "Green Intelligent Material (GIMs)" which belongs to the "Interreg IV France (Channel) - England" European programme. Authors thank Europe and the "Haute Normandie" Region for their financial and logistic supports.

\section{Appendix A. Supplementary data}

Supplementary data associated with this article can be found, in the online version, at http://dx.doi.org/10.1016/j.apsusc. 2013.06.123.

\section{References}

[1] S.M. Shang, Z. Li, Y. Xing, J.H. Xin, X.M. Tao, Preparation of durable hydrophobic cellulose fabric from water glass and mixed organosilanes, Applied Surface Science 257 (2010) 1495-1499.

[2] W. Huang, Y. Xing, Y. Yu, S. Shang, J. Dai, Enhanced washing durability of hydrophobic coating on cellulose fabric using polycarboxylic acids, Applied Surface Science 257 (2011) 4443-4448.

[3] M. Rinaudo, Main properties and current applications of some polysaccharides as biomaterials, Polymer International 57 (2008) 397-430.

[4] L.S. Costa, G.P. Fidelis, S.L. Cordeiro, R.M. Oliveira, D.A. Sabry, R.B.G. Câmara, L.T.B.D. Nobre, M.S.S.P. Costa, J. Almeida-Lima, E.H.C. Farias, E.L. Leite, H.A.O Rocha, Biological activities of sulfated polysaccharides from tropical seaweeds, Biomedicine \& Pharmacotherapy 64 (2010) 21-28.

[5] A. Cumashi, N.A. Ushakova, M.E. Preobrazhenskaya, A. D’Incecco, A. Piccoli, L. Totani, N. Tinari, G.E. Morozevich, A.E. Berman, M.I. Bilan, A.I. Usov, N.E. Ustyuzhanina, A.A. Grachev, C.J. Sanderson, M. Kelly, G.A. Rabinovich, S. Iacobelli, N.E. Nifantiev, A comparative study of the anti-inflammatory, anticoagulant, antiangiogenic, and antiadhesive activities of nine different fucoidans from brown seaweeds, Glycobiology 17 (2007) 541-552.

[6] E.B. Damonte, M.C. Matulewicz, A.S. Cerezo, Sulfated seaweed polysaccharides as antiviral agents, Current Medicinal Chemistry 11 (2004) 2399-2419.

[7] T.C.G. Azevedo, M.E. Bezerra, M.D. Santos, L.A. Souza, C.T. Marques, N.M Benevides, E.L. Leite, Heparinoids algal and their anticoagulant, hemorrhagic activities and platelet aggregation, Biomedicine \& Pharmacotherapy 63 (2009) 477-483.

[8] J.M. Goddard, J.H. Hotchkiss, Polymer surface modification for the attachment of bioactive compounds, Progress in Polymer Science 32 (2007) 698-725.

[9] J.L. Chen, Q.L. Li, J.Y. Chen, C. Chen, N. Huang, Improving blood-compatibility of titanium by coating collagen-heparin multilayers, Applied Surface Science 255 (2009) 6894-6900 
[10] Z. Zha, Y. Ma, X. Yue, M. Liu, Z. Dai, Self-assembled hemocompatible coating on poly (vinyl chloride) surface, Applied Surface Science 256 (2009) $805-814$.

[11] J.Jin, W.Jiang, Q. shi, J. Zhao, J. Yin, P. Stagnaro, Fabrication of PPgPEGMAgheparin and its hemocompatibility: from protein adsorption to anticoagulant tendency, Applied Surface Science 258 (2012) 5841-5849.

[12] W. Mussard, N. Kébir, I. Kriegel, M. Estève, V. Semetey, Facile and efficient control of bioadhesion on poly(dimethylsiloxane) by using a biomimetic approach, Angewandte Chemie International Edition 50 (2011) $10871-10874$.

[13] C. Mao, W.B. Zhao, A.P. Zhu, J. Shen, S.C. Lin, A photochemical method for the surface modification of poly(vinyl chloride) with $O$-butyrylchitosan to improve blood compatibility, Process Biochemistry 39 (2004) 1151-1157.

[14] A. Asadinezhad, I. Novák, M. Lehocký, F. Bílek, A. Vesel, I. Junkar, P. Sáha, A Popelka, Polysaccharides coatings on medical-grade PVC: a probe into surface characteristics and the extent of bacterial adhesion, Molecules 15 (2010) 1007-1027.
[15] Z.Zhou, M.E. Meyerhoff, Preparation and characterization of polymeric coatings with combined nitric oxide release and immobilized active heparin, Biomaterials 26 (2005) 6506-6517.

[16] A.K. Berresheim, M. Mattern-Klosson, W. Fresenius, A standard form of spectra for quantitative ESCA-analysis, Journal of Analytical Chemistry 341 (1991) $121-124$.

[17] N.R. James, A. Jayakrishnan, Surface thiocyanation of plasticized poly(vinyl chloride) and its effect on bacterial adhesion, Biomaterials 24 (2003) 2205-2212.

[18] T. Kameda, M. Ono, G. Grause, T. Mizoguchi, T. Yoshioka, Chemical modification and dechlorination of polyvinyl chloride by substitution with thiocyanate as a nucleophile, Polymer Engineering \& Science 50 (2010) $69-75$.

[19] J.D. Eick, R.J. Good, A.W. Neumann, Thermodynamics of contact angles II, Journal of Colloid and Interface Science 53 (1975) 235.

[20] J.F. Olivier, C. Huh, S.G. Mason, Effects of solid surface roughness on wetting, Colloids Surfaces 1 (1980) 79-104. 